\title{
Grammatical Parallelism in the Translation of Advertising Texts with Particular Reference to English and Arabic
}

\author{
Mohammad Issa Mehawesh ${ }^{1}$ \\ ${ }^{1}$ Faculty of Arts, Department of English Language and Translation, Zarqa University, Zarqa, Jordan \\ Correspondence: Mohammad Issa Mehawesh, Faculty of Arts, Department of English Language and Translation, \\ Zarqa University, PO box 132222, Zarqa 13132, Jordan. Tel: 962-7-9749-2506. E-mail: \\ mohammedissa33@yahoo.com
}

Received: April 6, 2013 Accepted: June 4, 2013 Online Published: August 1, 2013

doi:10.5539/ass.v9n10p254

URL: http://dx.doi.org/10.5539/ass.v9n10p254

This research is funded by the Deanship of Research and Graduate Studies at Zarqa University /Jordan.

\begin{abstract}
Advertising is a specific genre which uses many techniques to persuade no matter the circumstances. One of the techniques used in advertising is grammatical parallelism. This study is generally intended to investigate and describe grammatical parallelism in the translation of advertising texts with particular reference to English and Arabic. The study should also provide an insight into the techniques of advertising in two different cultures in order to demonstrate that the cultural background is evident in advertising. Furthermore, the study will point up some of the main problems posed by the translation of advertising texts, taking into consideration that advertising translation, both production and products, is a part of a socio-cultural system. We will also focus mainly on the textual part, particularly, grammatical parallelism in the translation of English and Arabic advertisements. We will draw in defining and describing grammatical parallelism on Jakobson model (1960).
\end{abstract}

Keywords: grammatical, parallelism, translation, advertisements

\section{Introduction}

Advertising is quite common in our modern society. We see, hear and read it everyday and everywhere around us. It is a special type of communication that conveys a message from the producer to the consumer. The aim of advertising is to be catchy and easy to be remembered. Thus, advertisements use specific linguistics devices to catch the attention and to establish a relationship with the consumer. Moreover, its aim is to gain attention, create interest and motivate reader to take an action (Boveè \& Arens, 1989: 26).

It goes without saying that advertising language, as a special register, is quite different from common language. It has its own features in morphology, syntax, and rhetorical devices. The language of advertising often uses figures of speech and other stylistic devices that are considered typical of poetic language. Leech (1966: 23) calls the language of advertising "loaded language", because of its intention to influence and change the will and the attitude of its receivers. A text is effective if it succeeds in achieving its purpose which is to convince the audience of the validity of certain opinions. In many ways, the language of advertising is, as we will see better below, a poetic language. Thus, the poetic functions of reiterated elements should be maintained in the translation of advertisements. In other words "[...] the aesthetic factor, if it exists in the original, must remain in the translation" (Newmark, 1981: 65). Moreover, the message of an advertisement needs to be remembered by the recipients and recognized as familiar. Thus, grammatical parallelism is one of the most frequent techniques used in advertising to enhance memorability.

Grammatical parallelism poses a particular challenge to the translators and thus preserving parallelism in the translation of advertising texts is undoubtedly crucial to their translation equivalence, because of its role in creating textual semantic unity. It is the empirical verification of the poetic function of language. Moreover, it has 'pervasive' rhetorical properties which advertising texts of all kinds make heavy use of. It is a very powerful device in advertising. It might produce the effect of emphasis on the important facts, make the text more rhythmical, outstanding and sometimes easier to remember. 


\section{Theoretical Background}

\subsection{What Is Advertising?}

Advertising is the non personal communication of information, usually paid for and usually persuasive in nature. Its goal is to persuade members of a particular market to buy a particular product or service (Boveè and Arens, 1994: 6).

The key words in the above definition are 'informing' and 'persuading'. In other words, the word advertising means 'drawing attention to something' and 'informing somebody'. In addition, advertising is not directed to individuals; it is directed to groups of people and reaches them through media.

By the same token, Bolen (1984: 9) defines advertising as paid, non personal communication through different mass media by business firms, non profit organizations and individuals who are in some way identified in the message in order to inform or persuade members of a community to buy a specific product or service. This means that the function of advertisements is to carry out a message which in its turn communicates a particular meaning by using signs that can be linguistic signs and/or non linguistic codes. Yeshin (2006: 3) states that Chartered Institute of Marketing defines advertising as [...] the management process responsible for identifying, anticipating and satisfying consumer needs profitability. Moreover, yeshin points out that for advertising to be effective and successful, it should deliver a persuasive message to a target audience. A more recent definition is provided by Sihui (2009: 261) who points out that advertising is a mean of [...] transporting the ways of life, customs, attitudes, mindsets and values of one culture across time and space to another culture.

On his part, Cook (2001: 221-223) claims that advertisements "have the typical instability of a relatively new genre", they are constantly changing "at the 'lower' levels of substance, surroundings, mode, and paralanguage, and also to some degree at the level of text where there is ever more skillful use of poetic devices such as parallelism", the reason for change being "an internal dynamic, changes in society, and changes in the genres on which they are parasitic or in which they are embedded".

Cook (2001) adds that advertisements inform, persuade, remind, influence and perhaps change opinions, emotions and attitudes. In other words, his contention is that advertisements do not only sell products but change society and make people buy things they do not want or need. He also feels that advertisements do give warnings or information to people. Hence, advertisements can help create awareness, construct identities and attitude.

\subsubsection{Structure of Advertisements}

\section{1) Headline}

Headline is the most important part of any advertisement. It attracts the reader attention so that the advertisers try to make it eye-catching and attractive to readers. Advertisers often use rhyme or parallelism in the headlines to make them stand out so that the reader goes on reading the rest of the advertisement. Thus, the advertisement should be easy to understand. Pop and Sim (2010: 187) introduce four stylistic features of headlines: conciseness, direct address, nominal or block style and active and positive approach. By conciseness, they mean that the headline must be short and brief. Direct address means a headline must be customer specific. By nominal or block style, they mean that the headline must be economical. Finally, the active and positive approach means that the headline should avoid the passive constructions and other misleading structures.

\section{2) Slogan}

The slogan is usually used to make the consumer remember it and connect it with a specific producer. Needless to say then that the slogan is an important element in advertising for is role in establishing a feeling of closeness between the advertisers and the consumers. Slogan usually consists of short sentences, employing parallelism, as we will see below, rhymes...etc to help the reader remember the phrase. The slogan is also known as [...] taglines, shares some similarities with headline, because some slogans come from successful headlines, explicit, refined and inflammatory are the features of slogan" (Yu, 2008: 8).

3) Body copy

Yu (2008: 7) says that the body copy [...] is the main part of advertising information, to find something useful". Furthermore, the text of the body copy [...] should relate to the campaign appeal and to the reader's self-interest, and it must explain the product or service being advertised satisfies the customer's need" (Bovée and Arens, 1994: 264). The slogan is the longest part in an advertisement. It can be long and short copy. Short copy is a brief description of the advantage of the product, whereas long copy provides the reader with more details about the product. 


\section{4) Logo}

Cook (2001: 62) points out that [...] some logos and ads exploit or slightly alter conventional letter shapes, to create an iconic representation of the product or of something associated with it". Logo is an important feature that exists in printed advertisements. It consists of a brand name and a slogan. It should be noted that the advertising does not necessarily confine to these elements because of the differences of advertised products and services, and the target audience.

\subsubsection{Objectives of Advertisements}

Generally speaking, the main goal of an advertisement is to capture the consumer's attention with the help of attention-seeking devices. Bovèe and Arens (1994: 218) provide us with five main objectives of advertising:

- Attention: a good advertisement should attract the consumers' attention to the product being advertised.

- Interest: the introduction and publicity of an advertisement should arouse consumers' great interest.

- Desire: the advertisement should stimulate consumers' desire to buy the product, and consequently, make them realize that this product is just what they need.

- Action: advertising's objective is to make consumers respond to the advertised information and evoke them to take the action of purchasing.

To sum up then, an important aspect of advertisements is the 'art of persuasion'- the ability to persuade people through the use of language. Language plays an important role in informing the consumers, convincing them of the benefits of the products or services and putting them into action. Thus, in the case of advertisements, the primary function is conative/ persuasive, but an important means of persuasion, as we will see below, often takes the form of parallelism; thus a 'poetic function' enters as well. In the previous sections, we have given an overview of advertising and structures of an advertisement. In the next section, we shall discus the functions of language in Jakobson's model, mainly poetic function.

\section{The Functions of Language}

The proper comprehension and interpretation of the source language text cannot be achieved without an analysis of the functions, in the sense of the 'rhetorical aims' which characterized the communication. As translators, we will be better prepared to identify the different functions of the original text, and therefore be solidly grounded to accurately reproduce in the target language the identical functions, so that our translation fulfils its own purpose.

\subsection{Beyond Conation: The 'Poetic Function' in Advertisements}

In his seminal paper, Roman Jakobson (1960) proposes a model of language which consists of six communicative functions and overlapping factors of language.

For Jakobson, for any speech event there are six possible functions: the conative, phatic, referential, emotive, poetic and metalingual - and six corresponding 'factors' which receive focus: the addresser, addressee, context, message, contact, and code, each of these overlapping, respectively, with one of the 'functions', as he sets out below. 


\section{FACTORS OF COMMUNICATION}

Context

Message

$\begin{array}{ll}\text { Addresser } & \text { Addressee } \\ \text { Contact } & \text { Code } \\ \text { CORRESPONDING SCHEME OF FUNCTIONS } & \text { Referential } \\ \text { Emotive } & \text { Poetic } \\ \text { Phatic } & \text { Meta-lingual } \\ \text { (or, Meta-textual) }\end{array}$

Figure 1. Adapted from Jakobson (1960: 353; 357)

The factors are hierarchically organized, depending on the nature of the event. In brief, (1) the referential function is oriented toward the context, (2) the emotive function is oriented toward the addresser, (3) the conative function is oriented toward the addressee, (4) the phatic function serves to establish, prolong or discontinue communication, in other words, it focuses on the contact that is made, (5) the metalingual function focuses on the code, to establish mutual agreement on the code, and (6) the poetic function focuses on the message itself (Jakobson, 1960: 356). The functions are not mutually exclusive; although one will typically be primary in any one text, overlap is the norm.

Jakobson's work has been adopted in various works on translation, such as that of Nida who argues that "[...] meaning must be understood primarily in terms of the functions performed by various factors in communication. Moreover, he adds that Jakobson's classification remains basic to an understanding of meaning (1975: 201). Thus, the functions of language must be understood in their entirety, but due space restrictions and the nature of our topic, we will concentrate here solely on the 'poetic' function of language which, perhaps surprisingly for some, is an important aspect of meaning in advertisements as well.

The poetic function is manifested in the way a message refers to itself, drawing the audience's attention to its structure and constituent part. Thus, the poetic function relates to the form or the 'how' of a message, which signs are used and how are they used to express the content of the communication. When the communication is oriented towards the form of the message or, to put it in another way, when the message fascinates by its form, then the poetic function dominates. We could also refer to this function as the 'aesthetic' function because it is intended to draw attention to the patterns of sound, meter, syntax, and so on, of the language used in the message. Rhyme, alliteration, punning, and even grammatical rule breaking are examples of the poetic function.

Jakobson tells us that "[...] the poetic function projects the principle of equivalence from the axis of selection into the axis of combination" (Jakobson, 1960: 358), and also that selection is based on equivalence, similarity and dissimilarity, synonymity and antonymy, whereas the combination is based on contiguity (1960: 358). In other words, the 'poetic' use of language involves placing together in sequence items which are phonologically or grammatically related. Patterns formed by the repetition of similar items will be both more common and more noticeable in poetry than in other kinds of language. Jakobson (1966: 399) assumes that "[...] on every level of language the essence of poetic artifice consists in recurrent returns". Indeed Jakobson sees the hallmark of poetry to be the organization of language on all levels - phonetic, morphology, syntactical, lexical, and phraseological into characteristics types of patterns. To this phenomenon he gives the name of Grammatical Parallelism, what he calls the empirical evidence of the poetic function (Jakobson, 1960: 358).

\subsection{Grammatical Parallelism}

In describing the nature of parallelism, Corbett and Connors (1999: 381) state that parallelism is " $[\ldots]$ the 
similarity of structure in a pair of series or related words, phrases or clauses". They (1999: 381) also adds "[...] parallelism is one of the basic principles of grammar and rhetoric". Parallelism provides means to emphasize meaning through the repetition of patterns. It has 'pervasive' rhetorical properties which advertisements of all kinds, make heavy use of.

Moreover, Jakobson (1968: 600) explains that "[...] parallelistic systems of verbal art give us a direct insight into the speaker's own conception of the grammatical equivalences". The same could be said of the phenomenon in any text type it occurs in - advertisements among them.

The vital notion, however, is that Grammatical Parallelism is considered to be a sort of semantic parallelism, i.e., it works not just at the level of the textual meanings, as grammatical parallelism gives a 'surfeit' of cohesive harmony, so that its importance lies in the reiteration of ideational and interpersonal meanings. In other words, Grammatical Parallelism "[...] is exploited rhetorically in contexts where strictly speaking it is not needed to realize the meaning at hand. The result is a 'surfeit' of cohesive harmony" (Martin, 1992: 386). In short, as Miller puts it

[...] the ultimate significance of grammatical reiteration is its capacity to call forth a corresponding recurrence of 'sense', so that GP, according to Jakobson, following up on Hopkins' 1865 insight, is seen to construe also, and at the same time, semantic parallelism (2007: 44).

Grammatical Parallelism is a 'poetic', rhetorical, as well as text-building, device. It is a tool that can be used either in intertwining a series of utterances that imply patterns of transitivity or in foregrounding contrastive images. Grammatical Parallelism is the empirical linguistic criterion of the poetic function (Jakobson, 1960: 358), consisting of reiteration of equivalents units, such as sounds, words, syntax, syllables, and metrical feet.

Torresi, (2010: 123) says that

[...] parallelism is recurrent syntactical similarity. Several parts of a sentence or several sentences are expressed similarly to show that the ideas in the parts or sentences are equal in importance. Parallelism also adds balance and rhyme and, most importantly clarity to the sentence.

She adds (2010: 123) the translator can play with sounds through assonance and consonance, i.e. [...] repetition of the same vowel or consonant sounds, of which rhyming is an advanced version". The translator can also play with sounds and alliteration which is [...] the recurrence of initial consonant sounds" and [...] play with language at the level syntax".

Looking at parallelism in Arabic language, it can be said that parallelism fulfills a principle locus in Arabic discourse in general and it is used regularly as a rhetorical device.In Arabic Language, grammatical parallelism is related to "rhymed prose" (المماتلة, موازنة) since it gives the structure a musical effect. This phenomenon is widely noticed in Arabic language as we will see below. It occurs when the form of one sentence, clause or phrase repeats the form of the other. It involves structural identity between two sections of a text. According to Beeston (1970: 112) Arabic language prose is distinguished by rhythmical balance between two clauses which are also marked by a careful parallelism of sense. Another description of parallelism in Arabic is introduced by Al-jubori (1984: 107). He points out that

[...] parallelistic forms in Arabic are often characterized with syndeton (i.e. a construction, parts of which are linked together by means of a connective), the most common syndetic connective being (wa). But occasionally asyndetic parallelistic forms are also used, creating a more forceful effect, mainly, we believe, through contrast with syndeton in other parts of the text.

Al Jubouri (1984: 107-108) divides parallelism into two types according to their degree of competence: complete parallelism where there is total or almost complete correspondence between the parallelistic structures, and incomplete parallelism where partial correspondence occurs between the parallelistic forms. On his part, El-Shiyab (1990: 273) points out that parallelism occurs in all text types in general, and in argumentative texts in particular. He (1990: 273) classifies parallelism into complete parallelism and cumulative parallelism. The former is achieved through having a complete correspondence in syntactic and semantic configurations of a pattern, whereas the latter is manifested when there is partial correspondence between the linguistic forms of the parallel constituents.

Another classification of parallelism is presented by Jawad (2007). In his classification, he includes two types: parallelism with anaphora (i.e. repeating initial lexical items in a parallelistic structure) and parallelism with synonymy. Moreover, Al-Nadjar (2007: 247-249) divides parallelism into three types: lexical parallelism, syntactic parallelism and phonological parallelism. Another classification of parallelism is presented by Johnstone (1991). She classifies parallelism into syntactic, morphological, semantic and phonological. She (1991) 
adds that parallelism and types of repetition are now-a-days out of style in English writing. They are means by which Arabic argumentative discourse is structured. By the same token, Al-Kufyshy (2006) views parallelism as one of the features that realizes textual cohesion. He argues that parallelism is more frequent in Arabic than it is in English.

Additionally, Holes points out [...] parallelism is associated with writers who see themselves as continuing the literary traditions of classical Arabic" (1995: 173). Furthermore, he adds (1995: 173) [...] Arabs recognize parallelism as evidence of writer's excellent style and command of the language".

\section{Data Collection and Methodology}

It should be noted that our method and materials are descriptive. Even though, there will be analysis of some examples to illustrate and describe grammatical parallelism in both English and Arabic. We have attempted to collect translated advertisements relevant to the present work from Alrai, Addustour and $\mathrm{Al}$ waseet newspapers over the period between January, 2012 and June, 2012. In other words, we have used those advertisements which contain features i.e. grammatical parallelism as worthy of analysis. In order to be considered a translation pair, the English and Arabic versions had to advertise the same product, have the same or very similar graphics, and contain written text. The set of English-Arabic advertisement pairs ranges from items advertising cosmetics and food.

\section{Translation of Advertisements}

One major problem regarding advertising is the proper translation of advertisements. The translation of some advertisements should not be a literal translation but rather than an adapted text. And to achieve adaptation in the target text, translators should have a general understanding about the text to be translated to determine the function of this text and have a similar effect on the receiving market. That is to say, in some cases, adaptation is the only way to make sure that the translation fits into the target culture situation (Nord, 1993: 60). Thus, translators should aim at producing an effective text to sell the advertised text in the target culture. In other words, "[...] equivalence does not necessarily mean fidelity to same text since the emphasis is not on staying close to the text, but on the advertisements" (Smith, 2002: 33). By the same token, Guidére (2006) points out translators adopt the strategy of adaptation for the sake of necessary functions such as managing cultural differences. In other words, translators of advertisements must pay attention to the socio-cultural aspects of the target market including religion, social habits and ethical norms. In a similar vein, Ho (2008: 192) says that translators of advertisements must not be extremely faithful to the original text because the main goal of an advertisement is to make customers purchasing the product. That is to say the translators have to manipulate the social and cultural values in order $t$ meet the target audience expectations. This idea emphasizes that the translator must be creative through adapting the strategy of adaptation.

Arens and Boveè (1994: 271-272) provide us with four basic rules that should be followed when translating advertisements:

- The translator must be an effective copywriter. It is not enough for the advertisers to have their advertisements only translated into the target language.

- The translator must have an understanding of the product, its features and its market.

- The translators should translate into their native language, and moreover, the translators should be resident of the target country to ensure the correct use of idiomatic phrases, of obeying culture and social attitudes.

- The original text of advertisement should be easy to translate. In other words, the text should not be ambiguous or contain idiomatic expressions.

In the light of the above, one can safely assert that language of advertising is closely connected to culture. That is to say when we deal with advertising language; we deal with culture. In order to effectively persuade the consumers to buy the advertised items, advertisers should bring cultural entertainment to consumers' lifestyle, beliefs, rituals and values. An advertisement should be consistent with the values of the consumers. Other wise, it will be rejected. For example, in Arabic countries, it is not acceptable to talk about intimate matters in advertising texts. Moreover, in Islamic regions, the use of the words pig and wine in a food campaign is not acceptable. To put it simply, the translator should choose emotive words that will suit the target audience. Marieke de Mooij (2004: 186) says [...] the concepts and ideas are embedded in the culture in which they originate. Words and sentences elaborated for one culture are not necessarily meaningful for another. As Simon puts it, [...] Translating advertising copy is like painting the tip of an iceberg ... and [...] advertising is not made of words, but made of culture" (In De Mooij, 2004: 180). 
Needless to say, then, words have meaning ultimately in terms of the culture in which they are used. Thus, all languages should be considered as being rooted in culture and understood in this context as well. All communication is conditioned by the constraints of the situation in culture, as is translation, especially as a form of cross cultural communication. In this perspective, Nord (1997: 1) states that [...] language is thus to be regarded as part of culture".

It goes without saying, then, that the translator needs to take into account the "[...] totality of the culture surrounding the act of text production and reception" (Hatim and Mason, 1990: 37). Schiffrin (1987: 4) confirms this view by stating that: "[...] language always occur(s) in a context, but its patterns - of form and function and at surface and underlying levels - are sensitive to features of that context." He continues, "[...] language is potentially sensitive to all of the contexts in which it occurs, and, even more strongly, language reflects those contexts because it helps to constitute them" (Schiffrin, 1987: 5). Thus, it is important while translating to take into consideration not only the lexical impact on the TL reader, but also the manner in which cultural aspects may be perceived. In other words, cultural implications for translation are important as lexical concerns and the language is the heart within the body of culture.

Indeed, when translating an advertisement into another language, we should study the consumers' behavior, cultural background, political views, religious beliefs, preferences, age, sex and so on. To put it simply, advertisements as commercial texts written to persuade, should be translated in a such way that the target text functions within the target culture as though it were an original (House, 1997:69).

From her side, Torresi (2010: 8-9) mentions the non-linguistic skills which are useful for translators of promotional and advertising texts. These non-linguistic skills are agility, persuasiveness, creativity, the knowledge of relevant laws and restrictions about the advertising in the countries where the translated text will be circulated and the ability to be flexible in the relationships one has with agencies, editors, and the end client.

One more point, when translating advertising material for international audiences, translators may either resort to internationalize the advertisement or to localize it. Interantionalization means [...] using the same strategy of communication in all targeted countries" (Guidére, 2003), and localization means [...] the processes by which a generic 'international' product is adapted to the requirements of a 'local', a place with a specific union of cultural and linguistic features" (Marato, 2007: 4).

It is clear from the forgoing discussion that the purpose of translating advertisements should be the same as that of producing advertisements. In addition, the translation of advertisements should function at the target market as the original advertisements do at the domestic market.

\subsection{Discussion}

As we have mentioned above, parallelism is popular in advertisements because it draws the ear; listeners are naturally attracted to its pleased sound. Thus, parallelism not only emphasizes an idea but also adds rhythm to a work and making it pleasing to hear or read. Furthermore, it can create expectation and excitement and is often used for emotive and persuasive effects; this rhetorical function can be achieved in various ways: syntactic parallelism, lexical parallelism and phonological parallelism. They are very effective means in drawing attention to form. Parallelism contributes to the way texts create meanings. To clarify what we mean, let us consider the following example:

\section{Example One:}

For oily hair

For dry hair

اللشعر الدهني

للشعر الناعم

As can be seen, the source text makes use of a great deal of grammatical parallelism. Firstly, there is repetition of select lexical items to reiterate and accumulate all the positive meanings being construed about them. The above text is characterized by the repetition of the words for and hair twice. Generally speaking, the primary function of the above text is conative (persuasive). Specifically here we have the aim of persuading potential client to buy the item offered: Shampoo. In Jakobson's terms, it is focused on the addressee.

In the Arabic target text, the translator succeeded in maintaining the parallel structures of the source text creating a rhythmic melody in a parallel construction, thus, an aesthetic rhetorical effect is regained in the target text. Consequently, the translation is equivalent, acceptable and natural. In other words, the translator succeeded in transferring equivalent effect as the original advertisement does. Thus, the translator of advertisement has an 
important role in the marketing and advertising wheel. That is to say, the translator is a receiver in the source language and culture and a receiver in the target language and culture. Therefore, the translator has to be aware of the cultural codes at work. He is the invisible negotiator between cultures. To illustrate more, let us consider the following example with its translation into Arabic:

\section{Example Two:}

Buy one and get one for free

واحدة علينا و الثانية عليك

As can be seen, the source text has two imperative parallel sentences combined by and in order to draw the consumer's attention to buy the product which is pizza. The advertiser here employed the imperative sentences to persuade readers to take action.

As for the translation, the translator succeeded in realizing the semantic and functional equivalent. By doing this, the translation tries to reproduce as much as possible the meaning and effects of the original text. The translator didn't resort to the literal translation because he might not be able to achieve the same effect in the translation. Moreover, the failure to translate parallelism means that advertisements lose some of their memorability and will not have positive impact on the target audience. Here, the translator made changes to the text. Yet, he kept the intended message with a higher effect on the target audience. And, as Hatim and Munday (2004: 10) point out:

$[\ldots]$ the sense may be translated, while the form often cannot. And the point where form begins to contribute to sense is where we approach untranslatability. This clearly is most likely to be in poetry, song, advertising, punning and so on, where sound and rhyme and double meaning are unlikely to be recreated in the target language.

To illustrate more, let us consider the following example:

\section{Example Three:}

Save more money and feed your family

وفر عالجيبة ... وطعمي العيلة

In this example, parallelism occurs in (save, feed) where the same grammatical structure is repeated in two parallel structures. Furthermore, morphological parallelism occurs in (money, family). As for the Arabic translation, it retained this structure; hence parallelism and rhyme are maintained. In many cases, morphologically parallel items can be found within syntactically parallel phrases or clauses. In these cases, they can contribute to parallelism on three levels: phonological, morphological, and syntactic.

Of particular interest here is not just the grammatical parallelism achieved, but also in the way the translator translated the two words (money, family) into (جيبة, عيلة). Generally speaking, the goal of an advertisement is to move the readers and to change their attitudes from skeptic to agreement. Thus, the psychology feelings of consumers must be set as a first priority. In other words, the functionality of the translation of the above example in the target culture rather than the equivalent effect of the translation to the source text was the translator's concern. Needless to say then, the traditional concept of "faithfulness" standard is not suitable for an advertisement translation. As Toressi (2010: 23) puts it

$[\ldots]$ in promotional texts, the concept of loyalty applies neither to the letter of the text, nor to its original content or message, but only to its intended function. If this function is not preserved, the target text is disloyal to the source text, even if its content and literal meaning are accurately conveyed. If, on the contrary, the function is maintained, then the translation can be deemed loyal to the original text, even if this implies creating and entirely new text, with a new form and a new content.

A further interesting example is taken from the commercial for Pizza:

\section{Example Four:}

Better Ingredients

\section{Better Pizza}

$$
\text { مكونات افضل ..... بيتز ا افضل }
$$

The English original displays anaphora with the repetition of better at the beginning of each clause. In the Arabic, the repetition is maintained in the two clauses. Thus, if a word is repeated in the original it should, if possible, be repeated in the translation, unless the context dictates a different translation for the repeated word. Here, the 
translator produced a literal translation in a parallel structure, but the translation is comprehensible and the senses explicit to the readers.

Parallelism may take various forms. To illustrate, let us consider the following example taken from an advertisement for a hair Shampoo (Pert Plus).

\section{Example Five:}

Incomparable quality

Unbeatable price

جودة لاتُقارن وسعر لائنافس

In this example, Parallelism is achieved through repetition of the same grammatical structure (Adjective, noun). This use highlights and underlines the parallel structure, creating greater impact on an audience and giving sense of completeness to the advertisement. As for the Arabic Target text, the parallel effect is created less by repeating the key attribute of the product than by rhythm and parallelism of the two passive verbs (يقارن, ينافس) and the negative particle (ل).

\section{Conclusion}

What the researcher hopes to have demonstrated in the study is that grammatical parallelism is an important tool to satisfy the readers aesthetically. It also serves as a potent tool of persuasion as a main source of the persuasive power in many advertisements. Moreover, grammatical parallelism is a tool to harmonize elements across texts. It assists readers by allowing them to anticipate, structurally and logically, what is going to come next. The value of grammatical parallelism goes beyond aesthetics. It points out the structure of the sentence, showing readers what goes with what and keeping them on the right track. Advertisements must be persuasive. Thus, rhetorical devices are to be expected. Finally, grammatical parallelism exists in both Arabic and English and it indicates similar grammatical structures. But parallelism in English has a different function; it operates as a figure of speech while in Arabic it is a text-structuring device.

\section{References}

Abdul-Raof, H. (2001). Arabic Stylistics: A Course Book. Wiesbaden: Harrassowitz Verlag.

Al-Jubouri, A. (1984). The Role of Repetition in Arabic Argumentative Discourse. In J. Swales, \& H. Mustapha. (Eds.), English for Specific Purposes in the Arab World (pp. 99-111). Birmingham: Aston University.

Al-Kufaishi, A. (2006). Lexical Cohesion Patterns in Arabic and English Expository Texts. Poznan Studies in Contemporary Linguistics Journal, 42, 7-33.

Al-Shiyab, S. (1990). The Structure of Argumentation in Arabic Editorial as a Case Study. Unpublished PhD thesis. Herriot-watt University, Edinburgh.

Arens, W. F., \& Bovee, C. L. (1994). Contemporary Advertising. Illinois: Irwin.

Beeston, A. (1970). The Arabic Language Today. London: Hutchinson and Co.

Beeston, A. (1974). Parallelism in Arabic Prose. Journal of Arabic Literature, V, 134-145. http://dx.doi.org/10.1163/157006474X00123

Bolen, W. H. (1984). Advertisment (2nd ed.). Newyork: John Wiley and Sons.

Cook, G. (2001). The Discourse of Advertising. London: Routledge, Taylor\& Francis Group.

Corbette, E. P. J., \& Connors, R. J. (1999). Classical rhetoric for the modern student (4th ed.). Oxford: Oxford University Press.

De Mooij, M. (2004). Translating Advertising: Painting the Tip of an Iceberg. Key Debates in the Translation of Advertising Material. The Translator, 10(2).

Guidére, M. (2003). The Translation of Advertisements: from Adaptation to Localization. Retrieved January 1, 2013, from http://www.translationdirectory.com/article60.htm

Hatim, B., \& Mason, I. (1990). Discourse and the Translator. London \& New York: Longman.

Hatim, B., \& Munday, J. (2004). Translation: An advanced Resource Book. USA \& Canada: Routledge.

Hiatt, M. (1973). The Prevalence of Parallelism: A Preliminary Investigation by Computer. In Language and Style, vi, 117-126.

Ho, G. (2008). Globalization and Translation: Towards a Paradigm Shift in Translation Studies. Germany: VDM 
Verlag Dr. Müller.

Holes, C. (1995). The Structure and Function of Parallelism and Repetition in Spoken Arabic: A Sociolinguistic Study. Journal of Semitic Studies, XL/1, 57-81. http://dx.doi.org/10.1093/jss/XL.1.57

House, J. (1997). A Model for Assessing Translation Quality. Meta, 22, 103-109. http://dx.doi.org/10.7202/003140ar

Jakobson, R. (1960). Closing statement: Linguistics and poetics. In T. A. Sebeok (Ed.), Style in language (pp. 350-377). Cambridge, Mass., MIT Press.

Jakobson, R. (1966). Grammatical parallelism and its Russian facet. Language, 42(2), 399-429. http://dx.doi.org/10.2307/411699

Jakobson, R. (1968). Poetry of grammar and grammar of poetry. Lingua, 21, 597-600. http://dx.doi.org/10.1016/0024-3841(68)90079-X

Jawad, H. A. (2007). Paraphrase, parallelism and chiasmus in Literary Arabic: Norms and translation strategies. Babel, 53(3), 196-215. http://dx.doi.org/10.1075/babel.53.3.02jaw

Leech, G. N. (1996). English in Advertising. London: Longman.

Marato, J. (2007). Multiple Dimensions of International Advertising: An Analysis of the Praxis in Global Marketing Industry from a translation Studies Perspective. Retrieved January 1, 2013, from http://www.euroconferences.info/proceedings/...2007_Marato_Jesus

Martin, J. R. (1992). English Text: System and Structure. Amsterdam and Philadelphia: Benjamins.

Miller, D. R. (2007). Construing the primitive primitively: grammatical parallelism as patterning and positioning strategy in D. H. Lawrence. In D. R. Miller, \& M. Turci (Eds.), Language and Verbal Art Revisited: Linguistic Approaches to the Study of Literature (pp. 41-67). London: Equinox.

Newmark, P. (1981). Approaches to Translation. Oxford: Pergamon.

Nida, E. A. (1975). Componential Analysis of Meaning: An Introduction to Semantic Structures. The Hague: Mouton.

Nord, C. (1991). Text Analysis in Translation. Amsterdam: Rodopi.

Nord, C. (1993). Translation as a Process of Linguistics. In addition, cultural Adaptation. In C. Dollerup \& Lindgaard (Eds.), Teaching Translation and Interpreting2: Insights, Aims, Visions. Amsterdam: John Benajamins.

Nord, C. (1997). Translating as a purposeful activity: Functionalist approaches explained. Manchester: St. Jerome.

Pop, A., \& Sim, M. (2010). The stylistics of Advertising. Fascicle of Management and Technological Engineering, 9(19), 183-188.

Schiffrin, D. (1987). Discourse markers. Cambridge: Cambridge University Press. http://dx.doi.org/10.1017/CBO9780511611841

Sihui, M. (2009). Translating the other: Discursive Contradictions and New Oriantalism in Contemporary Advertising in China. The Translator, 15(2), 261-282.

Smith, K. L. (2002). The Translation of Advertising Texts. A study of English Language Printed Advertisements and their Translations in Russian. Sheffield: University of Sheffield.

Torresi, I. (2010). Translating Promotional and Advertising Texts. Manchester, UK and Kinderhook (NY): St. Jerome Publishing.

Yeshin, T. (2006). Advertising. Mason, Ohio: Cengage Learning EMEA.

\section{Copyrights}

Copyright for this article is retained by the author(s), with first publication rights granted to the journal.

This is an open-access article distributed under the terms and conditions of the Creative Commons Attribution license (http://creativecommons.org/licenses/by/3.0/). 